\title{
A Simple Method for Evaluating the Sustainable Design of Energy Efficient Family Houses
}

\author{
Miha Praznik ${ }^{1, *}$ - Vincenc Butala ${ }^{2}$ - Martina Zbašnik-Senegačnik ${ }^{3}$ \\ ${ }^{1}$ Building and Civil Engineering Institute, Slovenia \\ 2 University of Ljubljana, Faculty of Mechanical Engineering, Slovenia \\ 3 University of Ljubljana, Faculty of Architecture, Slovenia
}

Buildings have negative effects on the environment throughout their life cycle, i.e. from the phase of obtaining raw materials and manufacturing materials and components up to the sale, building and use through the final phase of removal when the building is decommissioned. In general, current legislation limits both the use of energy and the emissions allowed during operation, but does not limit the other parameters that define the design of contemporary sustainable buildings. Determining the sustainability of buildings should take place in the planning phase of the project, when it is still possible to influence the outcome. In this article, a simplified method using five chosen indicators is employed to evaluate the level of sustainability. The areas to be evaluated are energy efficiency, use of primary energy, $\mathrm{CO}_{2}$ emissions, costs, and the level of living comfort achieved. The evaluation using these indicators is carried out using three subjective and objective weighting methods, such that the final evaluation includes the viewpoints of an independent evaluator and the points of view of both the user and the state.

In the case of an assessment of the five indicators for new constructions, it is ensured that the designs for the new building in energy class $A$ have the best total result of the assessment and therefore the best sustainable design, regardless of additional energy, environmental and economic investment during the building phase. With a suitable choice of heat supply, even new buildings in energy class $C$ can come close to the effectiveness of a building design in energy class $B$.

Keywords: energy efficiency, sustainable concept, single family house, efficiency evaluation, simplified method, primary energy use, $\mathrm{CO}_{2}$ emissions, living environment, life cycle cost

\section{INTRODUCTION}

The life cycle of every building can be divided into six phases: obtaining raw materials, manufacturing of materials and components, sale, construction, use and maintenance of the building, and demolition. Each of these phases creates a burden on the environment in the form of energy use, as well as of emissions of $\mathrm{CO} 2$ and other harmful or even dangerous substances. Individual phases of the cycle may take place at some distance from one another, which requires transportation. The use of energy and the associated emissions must therefore be looked at in the light of the entire life cycle of the building.

The built environment in Europe is responsible for 30 to $40 \%$ of the total use of primary energy. This represents a great potential for reductions in the use of energy, as well as in the emissions of $\mathrm{CO}_{2}$ [1]. In the past two decades society has become more aware of this and therefore European legislation is demanding more energy efficient buildings [2]. However, reducing the use of energy in buildings does not mean that the user faces decrease in living comfort. Sustainable development states that one must strive for buildings that provide equal or higher levels of living comfort with a limited use of natural resources and with the least possible negative effect on the environment throughout the building's total life cycle [3]. Users are becoming increasingly aware of this [4]. Buildings require energy both directly and indirectly. Directly, energy is needed in the construction, use and maintenance (operational energy), renovation and removal phases. Indirectly, energy is used to obtain the raw materials and manufacture the materials necessary to make the building and its technical installations functional (embodied energy). The percentage of energy needed in the construction, removal and transportation of materials phases is minimal [5] and is estimated to be around $1 \%$ of the total energy needed for the life cycle. The phases of recycling the building are not treated as part of the life cycle in the majority of studies [6].

The greatest percentage of the total energy use in the building life cycle is represented by the energy necessary for the use and maintenance of the building and the energy put into the building during construction. Studies show that for conventional buildings the operational energy is 85 to $95 \%$ of the total energy use over the lifetime of the building, which functions in a cycle of between 50 and 80 years [7] and [ 8]. This is particularly true for buildings in cold or moderate climates [9] and [10]. Embodied energy is more dominant in milder climates [11].

The most important measure for decreasing the amount of operational energy necessary is to 
increase the energy efficiency of the building [2]: with a greater thickness of built-in thermal insulation and windows with better thermal insulation, with an airtight thermal envelope, a building envelope without heat bridges, and the use of controlled ventilation with heat recovery. A number of types of energy efficient buildings have been developed using various concepts, such as very good low-energy houses, passive houses, zero-energy houses, self-sufficient houses, etc. Analyses by the authors show that the optimal type of energy efficient house is in fact the passive house [12]. The use of energy in the built environment will increase in the future due to the increase in the use of materials and new components [13].

The need for energy to heat spaces is strongly decreased in the most energy efficient buildings. The focus on energy savings comes from the decrease in the consumption of the final energy in the use and maintenance phase. However it is the energy necessary for the other phases of the life cycle of the building that is mostly disregarded [3]. The fact is that measures taken to decrease the operational energy necessary cause the increased use of energy in the phase of manufacturing of materials and components. Due to this, in the future more focus will have to be given to embodied energy. The total use of energy in low-energy buildings is, due to the higher percentage of embodied energy, even higher than in buildings with higher operational energy [14]. Measures to reduce the use of energy in the operation of the building therefore do not necessarily lower the primary energy use of the entire life cycle [13]. Therefore the choice of materials for a building with high energy efficiency becomes that much more important [15] and strategies for reducing the use of primary energy for the production of materials and components becomes key [16] and [17]. There are different ways mentioned in the literature to reduce the embodied energy of dwellings such as using low embodied energy materials, designing a lightweight/efficient structure to minimize material consumption, using recycled/ reusable materials, future refurbishment instead of demolition and use local sourced materials as much as possible. [18] and [19]

The negative effect of materials on the environment is defined by two basic environmental parameters, which should be included in the evaluation. The first is concerned with the use of primary energy from non-renewable resources that is necessary for the manufacture of building elements $\left(\mathrm{PEC}_{\text {n.r. }}=\right.$ primary energy content, non-renewable $)$. The second is concerned with the burden on the environment in the phase of manufacturing of building elements via substances having a greenhouse effect, i.e. a potential for global warming $\left(\mathrm{GWP}_{100}=\right.$ global warming potential, 100 years).

In addition to the energy and environmental parameters, the evaluation of the design of new buildings should also include economic and user parameters where suitable. The economic criteria, which is of key importance from the point of view of the owner and user, is usually the subject of a simultaneous optimization of the project energy efficiency, an investment in measures for efficient use, and use of renewable resources for the new buildings. Use of low embodied energy and cost effective building materials in the building construction can significantly reduce the overall energy consumption and investment [20]. The percentage of the investment going for costs over the whole life cycle can reach up to $70 \%$, therefore finding suitable concepts for energy efficient new buildings is of key importance [6] and [10]. The quality of the living conditions in contemporary new buildings can be indirectly increased by increasing their energy efficiency, however only through the use of suitable concepts for heating and ventilating spaces that take into account the specific characteristics of the new buildings.

A contemporary building must answer to a number of demands and therefore must be designed accordingly. In this article, a simple method is presented that allows us to check the suitability of the design of sustainable family houses using a small number of key chosen indicators. The simplicity of the new method ensures that planners use it in the design phase so that they seek the most optimal design for the building from the beginning.

\section{METHODOLOGY FOR CHECKING THE EFFICIENCY OF THE DESIGNS}

There are various parameters one can use to evaluate the choice of technologies for the design of contemporary family houses: living, economic, energy and environmental. These parameters complement one another, but they can also exclude, which is consequently felt in the overall evaluation of the concept for the new building. For an all-encompassing assessment of the rationality of the design for energy efficient family houses it is therefore of prime importance to recognize the interaction of the effects of the above parameters. In order to evaluate the design in the planning process stage, one must create a method for the quick evaluation of energy efficiency and a simple method for a comprehensive evaluation of the design. 
From the viewpoint of the wider and above all timely use of these new methods for the preliminary evaluation of designs, i.e. in the idea phase of the design, the simplicity and the ability to quickly obtain a smaller number of pieces of data for the calculation are the most important aspects of the method. This is the basic difference between the new methods and the current methods used for the energy efficiency evaluation of new buildings, for example the PHPP'07 tool, i.e. the Passive house planning package - the energy balance and Passive House design tool [21], and the existing approach to a comprehensive evaluation of building design, which is, in practice, in the form of a voluntary environmental certification such as TQB (Total Quality Building Assessment) in Austria [22], DGNB (German Sustainable Building Council) in Germany [23], CasaClima Nature in Italy [24], HQE (High Quality Environmental standard) in France [25], Minergie in Switzerland [26] and the wider use of the LEED (Leadership in Energy and Environmental Design) [27] and BREEAM (Building Research Establishment Environmental Assessment Method) systems [28]. The above methods are extremely complex, require a lot of data and evaluate the building only after construction is completed, when improving the quality of the building or rather the sustainability concept is no longer possible.

\subsection{Ranking Criteria and Methods of Ensuring Effective Design}

In this section the presented methodology comes out of a hierarchical ranking of various criteria and methods in order to ensure the efficiency concept in new buildings (Fig. 1). The criteria are ranked on three levels: primary, secondary and tertiary.

The primary and secondary levels have a cause and effect relationship. At the primary level the criteria for energy demands (use of heating to heat a building) are ranked, while at the second level the environmental criteria (use of primary energy and $\mathrm{CO}_{2}$ emissions), economic criteria (costs) and living criteria (thermal comfort and air quality) are ranked. For these two levels it is possible to use a new method for a comprehensive evaluation of the energy efficiency of a single-family house, presented in this article, using five indicators $\left(\mathrm{Q}_{\mathrm{nh}} / \mathrm{A}_{\mathrm{u}}, \mathrm{PEC}_{\mathrm{n} . \mathrm{r} .}\right.$, $\mathrm{GWP}_{100}$, Cost, LE) to identify the various effects on the building's life cycle. Due to disproportionality comes the decision to separate the evaluation of primary energy use and $\mathrm{CO}_{2}$ emissions. The difference appears in the evaluation of primary energy use and $\mathrm{CO}_{2}$ emissions in the production and installation of materials and components, for which the conversion factors are different. Furthermore, various conversion factors are used for different energy carriers as well.

Higher values for these indicators indicate a greater negative environmental or living effect, as well as a higher energy or cost burden. The values of the indicators are assigned to different scenarios of design ideas for new buildings. An individual indicator will have a maximal value for the least favourable scenario. From the viewpoint of sustainable design, the optimal solution has the lowest total value for the five indicators. Given the objective and subjective estimates of the criteria for the secondary

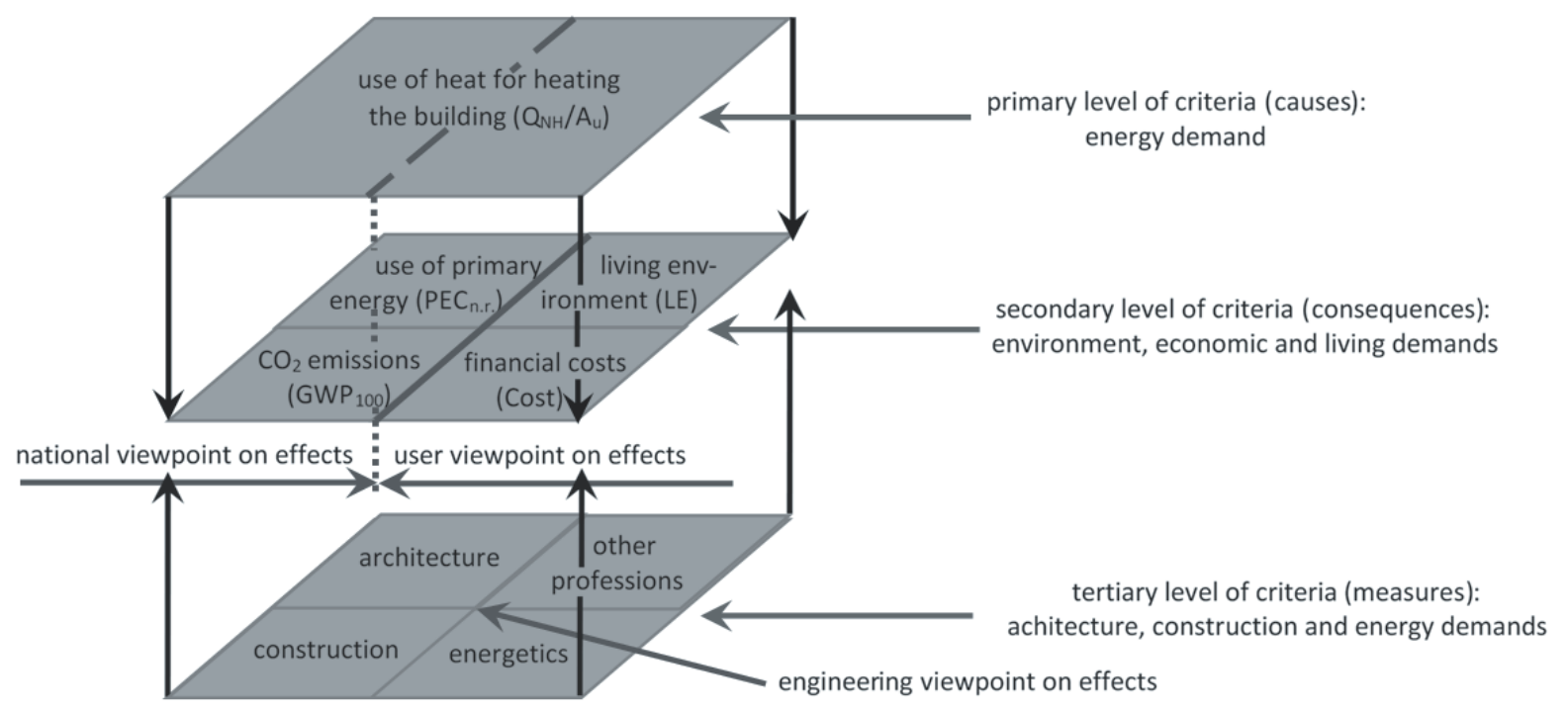

Fig. 1. Representation of the first two levels of demand or the criteria for evaluation using 5 key indictors 
level, the indicators can be shaped by weighting them differently. With an objective approach, all the indicators have an equal effect on the evaluation. From the subjective point of view of the user or the state demands for new buildings it is possible to give different indicators different effects in the process of evaluation.

In the ranking of criteria for the energy efficiency of new buildings we can, in the lower so-called tertiary level of criteria, rank the architectural and technological measures for achieving a higher level of energy efficiency and the measures for the co-use of renewable energy sources in the energy balance of the buildings. Research by the authors shows [29] that an effective design starts with the architecture of the building, such as defining the size of the building, heat zoning, floor-plan design, creating the building envelope, and the orientation of the glass parts of the facade of the building. Technological solutions for construction must then be sought, where it is equally important to weigh both the elements of construction joints from the viewpoint of heat protection achieved as from the point of view of the environmental burden, which is linked to the manufacture and construction of the materials themselves [30]. The heating and ventilation system must also be suitably adapted to the characteristics of new building. [31]. It is only through this that an energy efficient new building can reach its energy efficiency potential and create the optimal living conditions [32]. The heating system that provides heating for the building is of key importance for a comprehensive evaluation of the influences on the new building's life cycle. Analyses have shown [33] that the choice of systems for heat generation, which includes in large measure the use of renewable sources of energy, is of key importance. A suitable system for the generation of heat can also strongly influence improvements in the environmental and economic indicators in less energy efficient houses. In the case where such a system is used in energy efficient buildings built with wood and thermally insulated using natural materials, the wider environmental footprint of the building is minimal.

The key qualitative parameters through which the energy efficiency of the new building can be easily determined in the design phase should be placed at the level of the definition of measures, when calculations of the energy balance of buildings including the use of a larger number of known project parameters are otherwise not possible. The project leader must integrate the energy efficiency, environmental burden and investment in the construction of the building when choosing the technical building system, which is in practice only possible using simple procedures. Therefore, this phase of planning must incorporate knowledge of all relevant mechanisms.

\subsection{Indicators for a Comprehensive Evaluation of the Efficiency of Designs}

In energy efficient residential buildings we use various levels of indicators to show the rationality on many levels. By using the values of various indicators, which are ranked by criteria levels (Fig. 1), we can evaluate the wider effects of the designs of new buildings.

The starting point, i.e. the primary level of evaluation, is the energy efficiency of the building. This is the causal level, where only the indicator for the use of heat for heating the building $\mathrm{Q}_{\mathrm{NH}} / \mathrm{A}_{\mathrm{u}}$ is placed. This level of evaluation has been carried out in the past and used to judge the suitability of designs for new buildings (e.g. regulations concerning new buildings) and operations of buildings (e.g. energy check-ups for new buildings). The viewpoints and interests of the various parties involved in the evaluation are equal at this level.

On the secondary level of evaluations of buildings, which can be called the »effect " level, four indicators can be used to evaluate the key effects of the building on the use of primary energy, $\mathrm{CO}_{2}$ emissions, costs and living environment. This is a new level of evaluating buildings, which has not yet been applied in practice. Because the interests and priorities of the various parties involved (e.g. state, investors) are different with regard to the four indicators, the viewpoints at this level regarding the efficiency of the building design may be completely different. Consequently, the two involved parties may weigh the indicators used in the procedure to evaluate the building concept differently. For the user of the building, living comfort and costs are more important. While from the state point of view, the use of primary energy and $\mathrm{CO}_{2}$ emissions are regarded as more significant and therefore weighted more heavily.

The tertiary level of evaluating designs of new buildings concerns evaluating the engineering measures from various fields of expertise, which ensure that the demands of the primary and secondary levels are met. At this level we have to optimize and bring into accord the various indicators for architectural, construction and energy designs and take into account what constitutes efficiency from the point of view of the user and the state. The demands on this level are judged internally, only at the level of the involved professionals. Therefore it is not necessary 
to directly include this level of internal evaluation in the process of comprehensively evaluating buildings, since the results of the enacted measures are indirectly evaluated through their effects on the previous two levels.

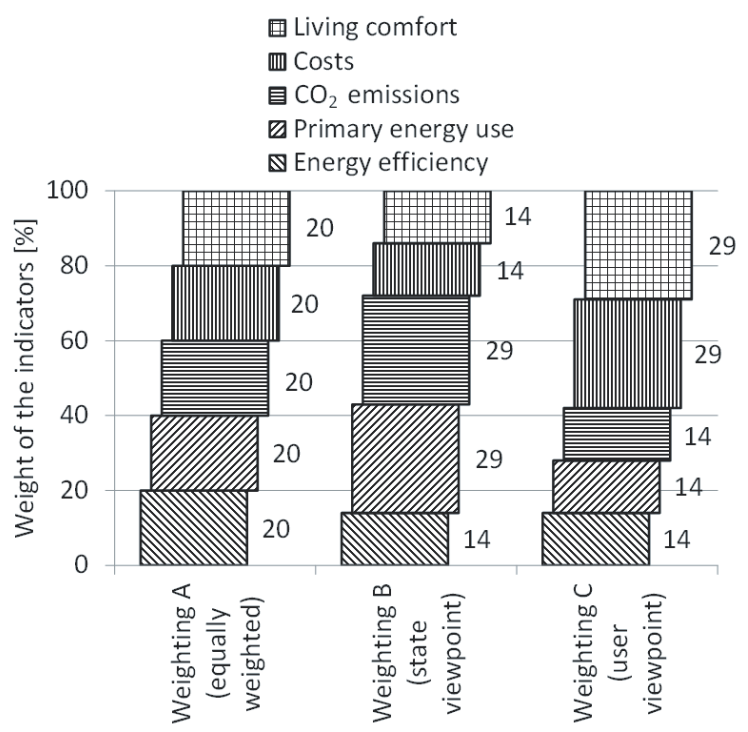

Fig. 2. Effects of weighting the five key indicators used in the building evaluation

Determining the effects of the project design of buildings using the five chosen indicators with values between 0 and $100 \%$, as shown in the first and second level of the criteria, is suggested in order to carry out a comprehensive evaluation of the rationality of a new building. Using the five indicators we can evaluate the effects of the building design on:

- the achieved energy efficiency: a lower level for indicator $\mathrm{Q}_{\mathrm{NH}} / \mathrm{A}_{\mathrm{u}}$ shows a higher energy efficiency of the design,

- the use of primary energy for the construction of the building and the generation of heat during operation: a low value for the $\mathrm{PEC}_{\text {n.r. }}$ indicator shows a higher environmental efficiency of the design,

- the generation of $\mathrm{CO}_{2}$ emissions in the manufacturing of materials and construction phase, as well as the generation of heat during operation: a low value for the $\mathrm{GWP}_{100}$ indicator means a lower environmental burden and therefore a higher environmental efficiency of the design,

- the costs for the construction of the new building and the energy costs for the generation of heat during operation of the building: a low value for the Cost indicator means a lower cost burden on the owner and use of the building and therefore a higher economic efficiency of the design,

- the indirect influence of the new building concept on living comfort: a low value for the LE (living environment) indicator means better living conditions and therefore a more suitable design for the user.

\subsection{Possible Approaches to Weighting the Indicators}

Different weighting proportions between the five indicators are shown comparatively for the objective evaluation and for both possible forms of the subjective evaluation, i.e. from either the state or user point of view (Fig. 2).

An independent evaluator can objectively assess the new building using an equal or equivalent weighting of all five indicators (Fig. 2, Weighting A). The two cases of subjective evaluation of the new building are typical and look as if they would arise out of a wider state viewpoint or from the viewpoint of the user of the building. In the first case, one assigns a double weighting to the indicators for the use of primary energy and $\mathrm{CO}_{2}$ emissions, which are most relevant from a state point of view (Fig. 2, Weighting B). In the second case (user), one assigns a double weighting to the indicators for costs and living comfort (Fig. 2, Weighting C).

\section{CALCULATION APPROACHES FOR DEFINING THE VALUES OF THE INDICATORS}

The values for the indicators are assigned as percentages when comparing the results obtained or estimated for various designs. Therefore, the highest value $(100 \%)$ for each of the indicators $\left(\mathrm{Q}_{\mathrm{NH}} / \mathrm{A}_{\mathrm{u}}\right.$, $\mathrm{PEC}_{\text {n.r. }}, \mathrm{GWP}_{100}$, Cost, LE) is assigned to the variant of the design that has the least favorable cumulative result. For the other variants of the design, the value of the indicator is proportionately lowered depending on the degree to which its results stand out from the maximal value for the comparable group of variants.

\subsection{Determining the Value of Indicator $\mathrm{Q}_{\mathrm{NH}} / \mathrm{A}_{\mathrm{u}}$}

The value of indicator $\mathrm{Q}_{\mathrm{NH}} / \mathrm{A}_{\mathrm{u}}$ is assigned on the basis of the result of the calculation or estimation of the energy balance of the building. A quick estimation of the building's energy need for heating can be obtained using a simple calculation method, given that one understands the key quantitative parameters of the design phase. In an article by the authors [34], a new calculating method for the simple estimation 
of energy consumption of buildings in a sample of 106 representative Slovenian highly energy efficient buildings was created using key qualitative parameters. An analysis of the correlations within the statistical sample of representative buildings in the study confirmed the assumption that for the estimation of energy consumption in contemporary singlefamily houses it is possible to use a small number of influential qualitative parameters linked to the design and use of the building, the characteristics of its heat envelope and the characteristics of the ventilation system. The new method can be used for a quicker evaluation in the form of two approaches depending on the available starting parameters. This approach for estimating the energy flows, which we can use in the above methodology, is linked to the parameters, which usually require a higher level of preparation of the starting data (Eq. (1)).

$$
\begin{gathered}
\mathrm{Q}_{\mathrm{NH}} / \mathrm{A}_{\mathrm{u}} \approx\left(78.3 \times \mathrm{H}_{\mathrm{T}}^{\prime} \times f_{d}+64.2 \times \mathrm{n}_{\mathrm{v}}\right)- \\
-\eta_{G} \times\left(4.9 \times \mathrm{q}_{\mathrm{i}} / \mathrm{A}_{\mathrm{u}}+78.7 \times \mathrm{ASF} / \mathrm{A}_{\mathrm{u}}-2.3\right) .
\end{gathered}
$$

These key parameters are: specific transmission heat loss coefficient of the building envelope $H^{\prime}{ }_{T}$ (W $\mathrm{m}^{-2} \mathrm{~K}^{-1}$ ), building envelope surface area to heated surface area ratio $f_{d}\left(\mathrm{~m}^{2} \mathrm{~m}^{-2}\right)$, total equivalent air exchange per hour in the building $n_{v}\left(\mathrm{~h}^{-1}\right)$, internal heat sources $q_{i}(\mathrm{~W})$, building treated floor area $A_{u}\left(\mathrm{~m}^{2}\right)$ and weighted window surface $A S F\left(\mathrm{~m}^{2}\right)$.

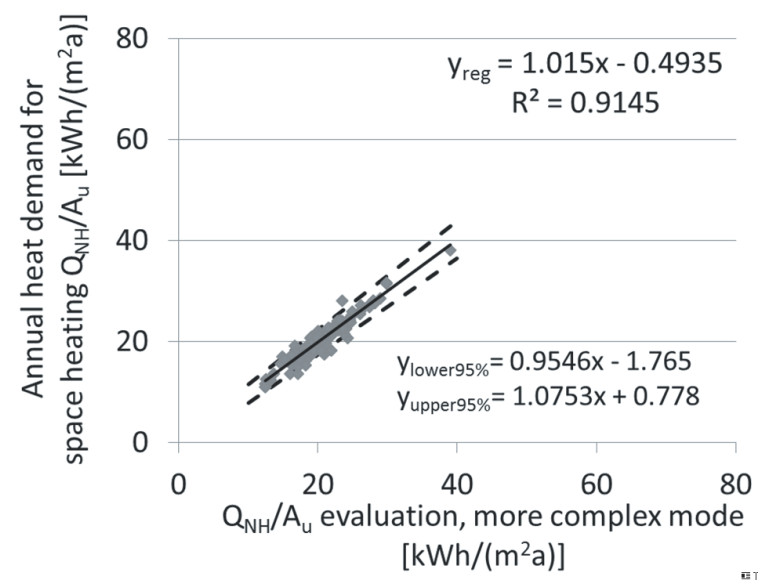

Fig. 3. Correlation between estimated heat demand for space heating and the actual calculated values

This is consequently seem in the higher correlation between the results of the evaluation, i.e. in their lower deviation from the actual calculated values, which are the real result of complex calculated energy balances (Fig. 3). Due to these characteristics, a more complex model is used in the preliminary evaluation of individual new buildings, e.g. when forming the key parameters for the idea design, identifying the effects of possible improvements or, in this case, when assigning the values of the indicator $\mathrm{Q}_{\mathrm{NH}} / \mathrm{A}_{\mathrm{u}}$.

\subsection{Defining the Value of the Indicators $\mathrm{PEC}_{n . r .}, \mathrm{GWP}_{100}$, and Cost}

In an environmental analysis of the building materials, building components and installation systems in new buildings we can limit ourselves to the time period of their manufacture. The project leader can obtain key data for all the planned systems for determining both environmental indicators (i.e. use of primary energy and $\mathrm{CO}_{2}$ emissions) using publicly accessible internet databases, e.g. ref. [35]. To further analyse the systems, one can also obtain any necessary data from the equipment producers and construction materials manufacturers regarding their investments in these areas for an on-going evaluation of the cost indicator.

We can limit ourselves to a period of 60 years when determining the value of the parameters in the building operation phase. From an estimation of the electrical energy use and fuel use that are necessary to generate heat, we can use known conversion factors [36] to estimate the consequent primary energy use and $\mathrm{CO}_{2}$ emissions, along with the associated estimated energy costs. In the above manner, we can also estimate in a simple manner the values according to the maintenance and upkeep of the building envelope and the energy systems for the time period of operation. On the basis of these values, we can also collect data on the consumption of primary energy, $\mathrm{CO}_{2}$ emissions and the associated costs.

\subsection{Defining the Value of Indicator LE}

In assessing the value of the indicator LE for different design variants, which are purely of a technological nature, it is not necessary to address the effects of architectural design, since it is the same for all cases. All treated variants have therefore equal conditions with respect to the architectural design of the glazing parts of the building envelope, orientation, and consequently their natural lighting of living spaces.

The value for indicator LE is assigned by evaluating the effects on living comfort in three areas:

- The achieved negative effect on the thermal comfort of the space, which is largely a consequence of the thermal protection offered by the building envelope, which is assigned a value from 0 to $35 \%$, for example $0 \%$ for variants 
with the highest efficiency thermal envelope or $35 \%$ for variants with a still acceptable level of thermal protection and temperature asymmetry. When allocating values, thermal comfort can be estimated in proportion to thermal envelope characteristics, e.g. calculated value $\mathrm{H}_{\mathrm{T}}^{\prime}, \mathrm{U}_{\mathrm{w}}$, etc.

- The negative effects of the planned heating system for ensuring thermal comfort are evaluated within the same size class. A value of $0 \%$ is assigned to a system with minimal negative effects on living comfort or $35 \%$ for a system with still acceptable functional characteristics. In the evaluation of the heating system effects on thermal comfort it is necessary to evaluate the characteristics of the designed systems. Those can have in certain combinations different effects. E.g. lowtemperature floor heating system in a low-energy house is in precedence over conventional radiator heating system, in a passive house floor heating system is less responsive and has more negative impact on the living comfort, as e.g. wall heating system or a heating system, which is integrated in the central ventilation [31].

- The third area concerns the negative effects of the means of ventilating spaces, which is expressed through a determination of air quality and associated living comfort. A value of $0 \%$ is assigned to a ventilation method with minimal negative effects and $30 \%$ to a ventilation system with an acceptable effect on living comfort. Assessing the impact of the ventilation system in the living comfort takes into account characteristics of different design solutions. Less favourable impacts on the living comfort usually has a natural ventilation system. E.g., central ventilation systems as well have an advantage over local systems. Systems with devices that enable high-heat recovery and humidity are in advantage over devices that only provide a less efficient heat recovery.

\section{CASES OF EVALUATIONS OF DESIGN METHODS USING THE PROPOSED METHOD}

Use of this method for a comprehensive evaluation of buildings using the five indicators is shown for five different energy efficiency concepts on one selected family house. Variants V1 to V5 of this model house have different energy efficiencies due to different thermal envelope components, different heat generation systems and different ventilation systems.

A single architectural model using a wooden construction, with a technologically modified heat envelope, different classes of targeted energy efficiency $\mathrm{Q}_{\mathrm{NH}} / \mathrm{A}_{\mathrm{u}}$ and different systems for heat generation, is used to allow comparisons between the buildings. Table 1 shows the key data. Other common parameters of the model family house are: heated area of the building $A_{u}=133 \mathrm{~m}^{2}$, thermal surface envelope $A=454 \mathrm{~m}^{2}$, window area $A_{w}=30 \mathrm{~m}^{2}$, shape factor fo $=0.68 \mathrm{~m}^{2} \mathrm{~m}^{-3}$.

- Variant V1 design fulfils the minimal energy efficiency demands. Due to the greater heat needs for heating the space, a more economical and environmentally efficient system was chosen to generate heat, i.e. a boiler apparatus with pellets and solar energy panels for providing hot sanitary water.

- Variant V2 has a more energy efficient building design. To maintain the investment value, a simple system for generating heat using fossil fuels was chosen, however this is less effective economically and environmentally in the long run.

Variant V3 is a very good low-energy building, where heat is generated by a heat pump.

- Variant V4 is designed as a standard passive house. The heating system is integrated into the ventilation system, which lowers the investment in installations.

- Variant V5 is a slightly improved new building both energy-wise and environmentally, at the standard of a passive house. In order to give the building better environmental indicators, the envelope is thermally insulated using cellulose flakes in place of mineral wool.

The analysed case refers to new construction in reference climate location for Slovenia (city Ljubljana, heating degree days $H D D=3100 \mathrm{~K} \mathrm{~d} \mathrm{a}^{-1}$ ). All data, linked to a reference location, are used in calculating the values for all indicators. For individual assessment of design concepts, as proposed by the method described, while evaluating the indicator $\mathrm{Q}_{\mathrm{NH}} / \mathrm{A}_{\mathrm{u}}$ and operating values for indicators $\mathrm{PEC}_{\text {n.r. }}, \mathrm{GWP}_{100}$ and Cost, it is necessary to use calculated values for all major parameters as they apply to the micro-location of a new construction.

The results of primary energy use, $\mathrm{CO}_{2}$ emissions and costs for the construction phase and operation are summed due to the integrity of the assessment concepts with indicators. The diagrams (Figs. 4 to 6) show their values comparatively, for the separate phases of the construction and operation. The results on primary energy consumption and $\mathrm{CO}_{2}$ emissions were, for the construction phase, calculated for each variant using the online tools [35]. For the operational phase the 
Table. 1. Key data presentation for the five different single family house design concepts

\begin{tabular}{|c|c|c|c|c|c|}
\hline Variant & V1 & V2 & V3 & V4 & V5 \\
\hline $\mathrm{Q}_{\mathrm{NH}} / \mathrm{A}_{\mathrm{u}}\left[\mathrm{kWh} /\left(\mathrm{m}^{2} \mathrm{a}\right)\right]$ & 50 & 40 & 25 & 15 & 10 \\
\hline $\mathrm{U}_{\mathrm{m}}\left[\mathrm{W} /\left(\mathrm{m}^{2} \mathrm{~K}\right)\right]$ & 0.25 & 0.21 & 0.20 & 0.16 & 0.14 \\
\hline $\mathrm{U}_{\mathrm{W}}\left[\mathrm{W} /\left(\mathrm{m}^{2} \mathrm{~K}\right)\right]$ & 1.0 & 0.90 & 0.90 & 0.75 & 0.75 \\
\hline $\mathrm{n}_{50}\left[\mathrm{~h}-1^{-1}\right]$ & 1.0 & 1.0 & 0.8 & 0.6 & 1.0 \\
\hline \multicolumn{6}{|c|}{ Materials: } \\
\hline Window frames & PVC & PVC & wood & wood & wood \\
\hline Thermal envelope & $\begin{array}{l}\text { expanded polystyrene } \\
\text { and mineral wool }\end{array}$ & $\begin{array}{l}\text { expanded polystyrene } \\
\text { and mineral wool }\end{array}$ & mineral wool & $\begin{array}{l}\text { mineral wool and } \\
\text { extruded polystyrene }\end{array}$ & $\begin{array}{l}\text { cellulose flakes and } \\
\text { extruded polystyrene }\end{array}$ \\
\hline Ventilation system & natural ventilation & natural ventilation & $\begin{array}{l}\text { mechanical with } 85 \% \\
\text { heat recovery }\end{array}$ & $\begin{array}{l}\text { mechanical with } 90 \% \\
\text { heat recovery }\end{array}$ & $\begin{array}{l}\text { mechanical with } 90 \% \\
\text { heat recovery }\end{array}$ \\
\hline Heat generation & $\begin{array}{l}\text { pellets boiler, thermal } \\
\text { solar system }\end{array}$ & $\begin{array}{l}\text { gas condensing boiler, } \\
\text { thermal solar system }\end{array}$ & $\begin{array}{l}\text { heat pump, horizontal } \\
\text { ground collector }\end{array}$ & $\begin{array}{l}\text { heat pump, horizontal } \\
\text { ground collector }\end{array}$ & $\begin{array}{l}\text { heat pump, horizontal } \\
\text { ground collector }\end{array}$ \\
\hline Heating system & radiator system & radiator system & floor heating & integrated in ventilation & integrated in ventilation \\
\hline
\end{tabular}

latter was determined according to the annual use of energy carriers using data from energy distributors and certain national conversion factors [36]. Data on investment for individual variants were obtained from the selected contractor, which excludes divergences

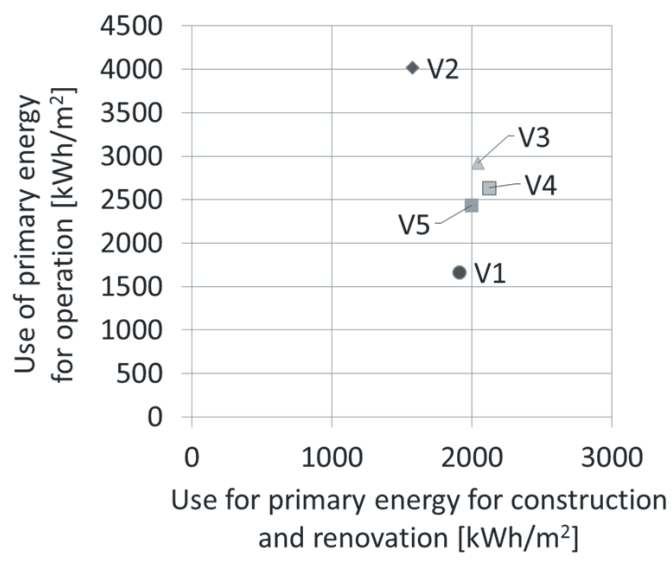

Fig. 4. The use of primary energy for the five variants (60 year period)

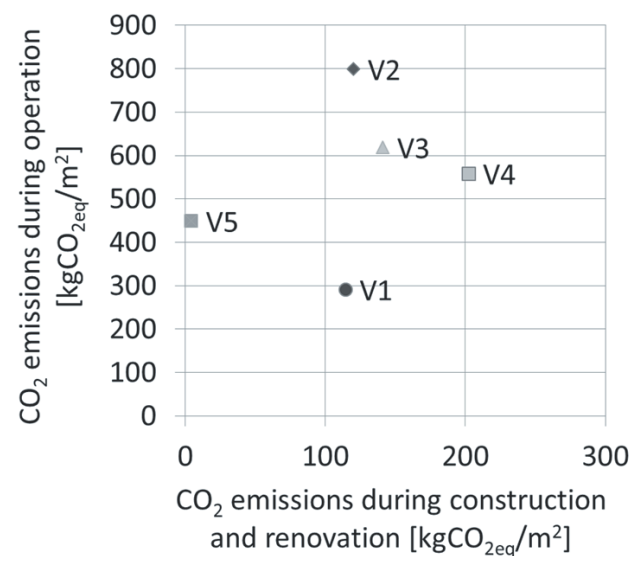

Fig. 5. $\mathrm{CO}_{2}$ emissions for the five variants (60 year period) in the assessments by different companies. The data related to renovation and modernization are evaluated according to the inventory of necessary works on the building over the years. E.g. depending on the lifetime it is necessary to replace equipment and components in the systems of heat generation and ventilation, foreseen are as well works on maintaining the outer surfaces of the thermal envelope and such alike.

The data forming the basis for the assignment of the values of indicators PECn.r., GWP100 and Cost are calculated for the five variant building designs and are shown (Figs. 4 to 6) from the viewpoint of the investment (construction and renovation) and operation. On the basis of this data, the value of the indicators is assigned, which are then compared for all five designs for new buildings (Fig. 7).

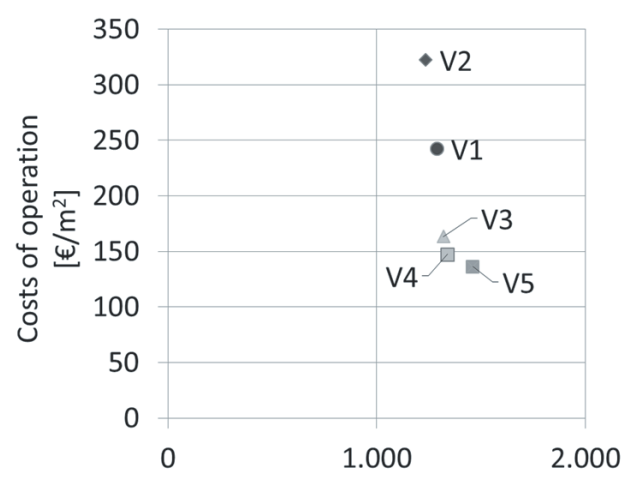

Costs of construction and renovation $\left[€ / \mathrm{m}^{2}\right]$

Fig. 6. The costs for the five variants (60 year period)

Primary energy consumption and associated $\mathrm{CO}_{2}$ emissions for the transportation of building materials in the analysed case have not been taken into account. This stems from the specifics of the construction 


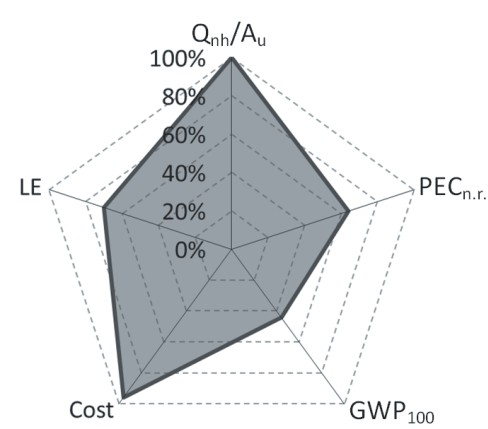

(V1)
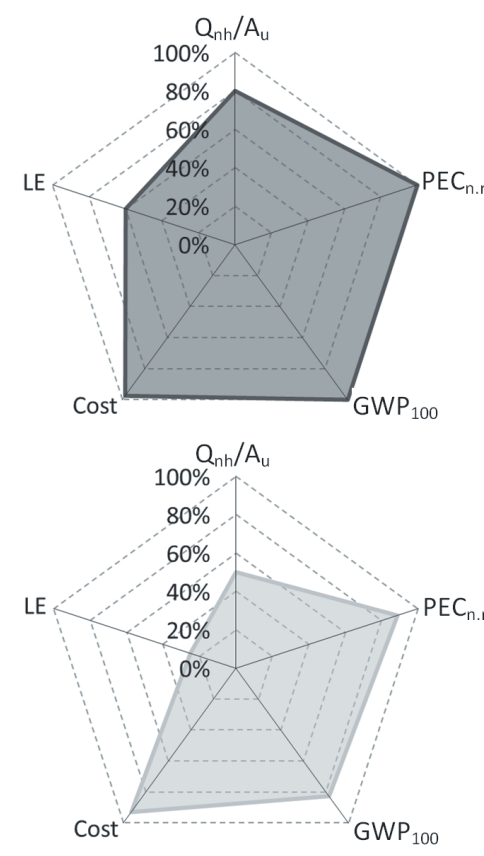

(V2)

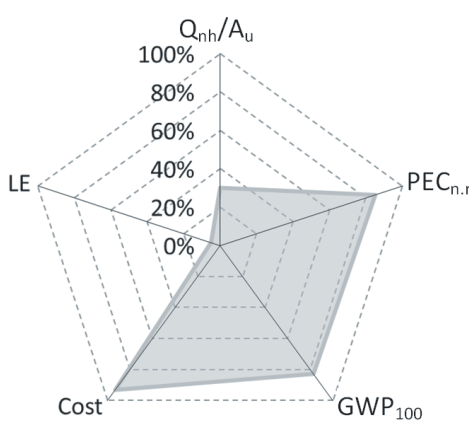

(V3)

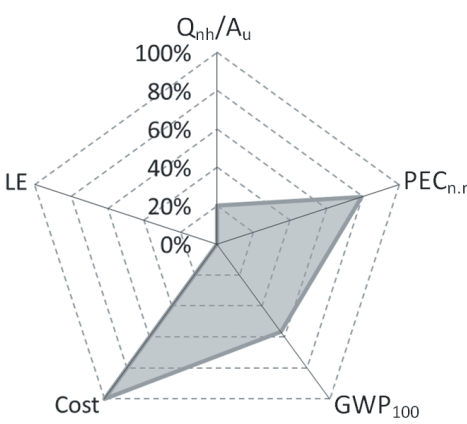

(V4)

Fig. 7. Comparison of the evaluation of indicators for the new building variants with different indicator weightings of family houses in Slovenia, for which almost exclusively apply building materials and products of domestic manufacturers (e.g., wood, brick, concrete, thermal insulation, windows), which are typically produced within a radius up to $150 \mathrm{~km}$ depending on the location of new buildings. When at design stage the use of components and materials is intended, which clearly reflect the increasing energy needs for transportation, the designer must consequently take this into account in the calculation, as this is an integral part of the total energy requirements during the construction phase of the building.

A comprehensive evaluation of the different design variants can take place in the three previously described manners. In the objective evaluation (Weighting A), all indicators have the same weighting in the total score. In the two subjective approaches to the evaluation (Weighting $\mathrm{B}$ and $\mathrm{C}$ ), the indicators are given different weightings (Fig. 8) according to the different viewpoints of those involved.

These results confirm the assumption that the optimized design concept for the most energy efficient new building, which is represented by both passive house variants (V4 and V5), also has the best or rather the lowest total score for the comprehensive evaluation, which also parallels the objective and both subjective evaluation methods.

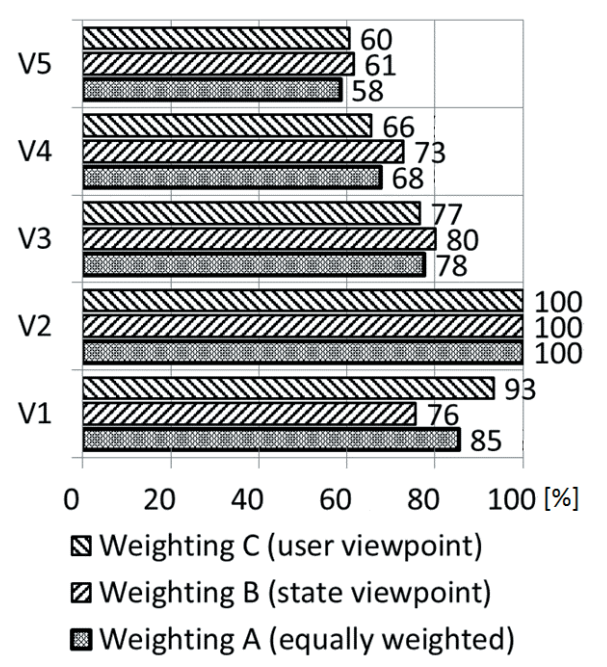

Fig. 8. Graph of the values for five key indicators for five variant designs for new buildings

For variant V5, the results of the evaluation are between 58 and $61 \%$ (Fig. 8), and for variant V4 between 66 and $73 \%$. The very good low energy house concept (variant V3) comes next and is ranked third with a score between 77 and $80 \%$ for the comprehensive evaluation according to the three 
assessment methods. The worst result of the total evaluation was the less energy efficient new building (variant V2), where heat was mostly generated using fossil fuels. This amount $(100 \%)$ is the total for all three weighting methods. A comprehensive evaluation of the designs also confirms that even a less energy efficient new building (variant V1) can be improved by applying suitable correctional methods of thermal supply, i.e. by using totally renewable sources of energy. Variant V1 achieved a score of between 76 and $93 \%$ due to this kind of measure.

\section{CONCLUSION}

Energy efficient family houses generally provide residents a high quality of living comfort, thus thermal comfort, daylight and air quality. Improved thermal insulation of the building envelope ensures appropriate internal surface temperatures. Architectural solutions in the design of the building envelope include larger glazing surfaces, thereby more daylight. A central ventilation system, that all buildings have, continuously ensures the quality of air in living spaces. To maintain the expected temperatures in living spaces is of paramount importance to plan adequate heating system and its control, which should enable dynamic adaptation to changes in individual rooms. It should be stressed that the first step to provide efficient concept for modern family house is optimal architectural design. By exploiting the natural resources of new construction's micro location and with the appropriate building design and orientation, we define any consequential energy requirements and technological measures. Before using the presented method is therefore necessary to ensure that all previous architect's decisions were optimal. Only after this verification of the architectural concept, we are able to design different technological variants, which are subject to assessment by the presented method.

The demand for higher energy efficiency in new single family houses can be understood as the need for heat to heat spaces $\left(\mathrm{Q}_{\mathrm{NH}} / \mathrm{A}_{\mathrm{u}}\right)$, which is fundamental and at the same time an established criteria for judging the design of new buildings in Slovenia. The judgement of designs for new buildings include the regulations set by domestic legislation in the area of energy efficient buildings [37] and the methodology for determining the energy characteristics of buildings [38], as well as the fulfilment of criteria for allowed primary energy use and emissions of $\mathrm{CO}_{2}$ during the operation of the building. The above three criteria, which are checked via calculations during the planning process for the new building, only concern the operation of the building. Because these calculations do not take into account the other phases of the building life cycle, this kind of evaluation is not complete or rather not comprehensive enough from the point of view of sustainable design for new buildings.

With the aim of creating a timely and comprehensive evaluation of the design for contemporary new buildings, a simple methodology has been developed that can be used by project planners at the starting phase of planning. Five key indicators are used to evaluate different variants of conceptual designs for new buildings, whose values are determined using simple calculation methods. The values are determined for the operation phase and the construction and renovation phase. Presented method for assessing different concepts of energy efficient family houses is straightforward. It is intended for experienced engineers who use the software for the design of modern family houses [21] and [35], and simple calculations to obtain the information necessary to assign a value to each indicator. The method is designed to assess the concepts of the family house. For the evaluation of more complex cases, which are typically larger public or commercial buildings, with a similar approach, it would be necessary to introduce additional indicators that are not needed for the modern family houses (e.g. related to the use of energy for cooling). The aim of using this method is to obtain a preliminary assessment for the various designs, which includes the living, economic, energy and environmental parameters.

Using the obtained evaluation the project planner and investor can decide to choose those design variants with the best total result in a rational way. It is demonstrated in this paper that with using an optimal combination of different characteristics of the chosen variant proves to be the most sustainable design.

The results of the evaluation using the new methodology in the case of different design variants for family houses show that the solutions for the most energy efficient building (two design variants of passive houses in energy classes A1 and A2) have the best total result out of the assessment, taking into account the objective and subjective methods of evaluation. A precondition for such a favourable result is the optimization of the building construction and of the kind of heat supply used. By using materials that are more environmentally friendly in the phase of manufacturing and building (e.g. wood, cellulose insulation), we can ensure fewer negative effects for highly energy efficient buildings by comparison with less energy efficient new buildings. By using suitable 
heat supply systems, which utilize renewable sources of energy (e.g. wood biomass, solar radiation), we can decrease the negative effects over the total life cycle, even for less energy efficient buildings (the design variant with energy class C) and come close to the effectiveness of more energy efficient buildings (design variant in energy class B).

\section{REFERENCES}

[1] European Commission (2006). Action Plan for Energy Efficiency: Realising the Potential, from http:// ec.europa.eu, accessed on 2010-06-09.

[2] Directive 2010/31/EU of the European Parliament and of the Council of 19 May 2010 on the energy performance of buildings (recast) (2010). Official Journal of the European Union, L 153/13.

[3] Gustavsson, L., Joelsson, A. (2010). Life cycle primary energy analysis of residential buildings. Energy and Buildings, vol. 42, no. 2, p. 210-220, DOI:10.1016/j. enbuild.2009.08.017.

[4] Kitek Kuzman, M., Motik, D., Bičanić, K., Vlosky, R.P., Oblak, L. (2012). A comparative analysis of consumer attitudes on the use of wood products in Slovenia and Croatia. Drvna industrija (Wood Technology), vol. 63, no. 2, p. 71-79.

[5] Vujicic, A., Zrnić, N., Jerman, B. (2013). Ports sustainability: A life cycle assessment of zero emission cargo handling equipment. Strojniški vestnik - Journal of Mechanical Engineering, vol. 59, no. 9, p. 547-555, DOI:10.5545/sv-jme.2012.933.

[6] Sartori, I., Hestnes, A.G. (2007). Energy use in the life cycle of conventional and low energy buildings: a review article. Energy and Buildings, vol. 39, no. 3, p. 249-257, DOI:10.1016/j.enbuild.2006.07.001.

[7] Feist, W. (1997). Life cycle energy analysis: comparison of low-energy house, passive house, self-sufficient house. Protokollband, no. 11, p. 1-13, Passivhaus Institut, Darmstadt.

[8] Citherlet, S., Defaux, T. (2007). Energy and environmental comparison of three variants of a family house during its whole life span. Building and Environment, vol. 42, no. 2, p. 591-598, DOI:10.1016/j. buildenv.2005.09.025.

[9] Winther, B.N., Hestnes, A.G. (1999). Solar versus green: the analysis of a Norwegian row house. Solar Energy, vol. 66, no. 6, p. 387-393, DOI:10.1016/ S0038-092X(99)00037-7.

[10] Scheurer, C., Keoleian, G.A., Reppe, P. (2003). Life cycle energy and environmental performance of a new university building: modeling challenges and design implications. Energy and Buildings, vol. 35, no. 10, p. 1049-1064, DOI:10.1016/S0378-7788(03)00066-5.

[11] Karimpour, M., Belusko, M., Xing, K., Bruno, F. (2014). Minimising the life cycle energy of buildings: Review and analysis. Building and Environment, vol. 73, p. 106-114, DOI:10.1016/j.buildenv.2013.11.019.
[12] Schnieders, J., Hermelink, A. (2006). CEPHEUS results: measurements and occupant's satisfaction provide evidence for Passive Houses being an option for sustainable building. Energy Policy, vol. 34, no. 2, p. 151-171, DOI:10.1016/j.enpol.2004.08.049.

[13] Dodoo, A., Gustavsson, L., Sathre, R. (2011). Building energy-efficiency standards in a life cycle primary energy perspective. Energy and Buildings, vol. 43, no. 7, p. 1589-1597, DOI:10.1016/j.enbuild.2011.03.002.

[14] Feist, W. (1996). Life-cycle energy balances compared: low-energy house, passive house, self-sufficient house. Proceedings of the international symposium of $C I B$ W67, Vienna, p. 183-190.

[15] Thormark, C. (2002). A low energy building in a life cycle - its embodied energy, energy need for operation and recycling potential. Building and Environment, vol. 37, no. 4, p. 429-435, DOI:10.1016/S03601323(01)00033-6.

[16] Sokolović, S.M., Zavargo, Z.Z., Sokolović, D.S. (2012). Sustainable development, clean technology and knowledge from industry. Thermal Science, vol. 16, iss. Supplement, p. 131-139, DOI:10.2298/ TSCI120130067S.

[17] Palčič, I., Pons, M., Bikfalvi, A., Llach, J., Buchmeister, B. (2013). Analysing energy and material saving technologies' adoption and adopters. Strojniški vestnik - Journal of Mechanical Engineering, vol. 59, no. 6, p. 409-417, DOI:10.5545/sv-jme.2012.830.

[18] Kitek Kuzman, M., Grošelj, P. (2012). Wood as a construction material: comparison of different construction types for residential building using the analytic hierarchy process. Wood research, vol. 57, no. 4, p. 591-600.

[19] Rossi, B., Marique A.F., Reiter, S. (2012). Life cycle assessment of residential buildings in three different European locations, case study. Building and Environment, vol. 51, May 2012, p. 402-407, DOI:10.1016/j.buildenv.2011.11.002.

[20] Bansal, D., Singh, R., Sawhney, R.L. (2014). Effect of construction materials on embodied energy and cost of buildings - A case study of residential houses in India up to $60 \mathrm{~m} 2$ of plinth area. Energy and Buildings, vol. 69,p. 260-266, DOI:10.1016/j.enbuild.2013.11.006.

[21] PHPP (2007). Passive House Planning Package - The energy balance and Passive House design tool. Passive House Institute, Darmstadt.

[22] ASCB - Austrian Sustainable Building Council. TQB Total Quality Building Assessment, from https://www. oegnb.net/en/home.htm, accessed on 2012-12-20.

[23] DGNB Deutsche Gesellschaft für Nachhaltiges Bauen e.V. $=$ German Sustainable Building Council - GeSBC, from $h t t p: / / w w w . d g n b . d e / e n /$, accessed on 2012-12-20.

[24] KlimaHaus/CasaClima Agency = ClimateHouse Agency, from http://www.klimahaus.it/en/ climatehouse/1-0.html, accessed on 2012-12-20.

[25] Association HQE, High Quality Environmental standard, from http://assohqe.org/hqe/, accessed on 2012-12-20. 
[26] MINERGIE®, Association Minergie/Verein Minergie (AMI), from http://www.minergie.ch/home_en.html, accessed on 2012-12-20.

[27] The Leadership in Energy and Environmental Design (LEED) Green Building Rating System, U.S. Green Building Council (USGBC), from http://www.usgbc. org/LEED/, accessed on 2012-12-20.

[28] BREEAM (BRE Environmental Assessment Method), Building Research Establishment, from http://www. breeam.org/about.jsp?id=66, accessed on 2012-12-20.

[29] Praznik, M., Zbašnik-Senegačnik, M. (2011). Analysis of qualitative parameters for energy-efficient houses. AR Architecture, Research, vol. 2, p. 1580-5573. (in Slovene)

[30] Gustavsson, L., Joelsson, A. (2010). Life cycle primary energy analysis of residential buildings. Energy and Buildings, vol. 42, no. 2, p. 210-220, DOI:10.1016/j. enbuild.2009.08.017.

[31] Feist, W., Schnieders, J., Dorer, V., Haas, A. (2005). Re-inventing air heating: Convenient and comfortable within the frame of the Passive House concept. Energy and Buildings, vol. 37, no. 11, p. 1186-1203, DOI:10.1016/j.enbuild.2005.06.020.

[32] Dovjak, M., Shukuya, M., Krainer, A. (2012). Exergy analysis of conventional and low exergy systems for heating and cooling of near zero energy buildings.
Strojniški vestnik - Journal of Mechanical Engineering, vol. 58, no. 7-8, p. 453-461, DOI:10.5545/svjme.2011.158.

[33] Feist, W. (2004). Neue Passivhaus - Gebäudetechnik mit Wärmepumpen. Protokollband Nr. 26. Passivhaus Institut, Darmstadt.

[34] Praznik, M., Butala, V., Zbašnik-Senegačnik, M. (2013). Simplified evaluation method for energy efficiency in single-family houses using key quality parameters. Energy and Buildings, vol. 67, p. 489-499, DOI:10.1016/j.enbuild.2013.08.045.

[35] Baubook - Rechner für Bauteile, from http://www. baubook.at/, accessed on 2013-09-20.

[36] Ministry of Environment and Spatial Planning, Technical guideline TSG-1-004:2010, Efficient use of energy, from: http://www.mzip.gov.si/fileadmin/mzip. gov.si/pageuploads/zakonodaja/graditev/TSG-01004_2010.pdf, accessed on 2012-12-20. (in Slovene)

[37] Rules on efficient use of energy in buildings with a technical guideline (2010). Official Gazette of the Republic of Slovenia, no. 52/2010. (in Slovene)

[38] Regulations on the methodology of producing and issuing energy performance certificates of buildings (2009). Official Gazette of the Republic of Slovenia, no. 77/2009. (in Slovene) 